\title{
Young Stroke Prevention Program for University Lecturers with Risk Factors via Smartphone Application
}

\author{
Tharisara Chirasatienpon \\ Department of Physical Education, Faculty of Education, Kasetsart University, Bangkok, Thailand \\ Email: fedutac@ku.ac.th, tharisara89@gmail.com
}

How to cite this paper: Chirasatienpon, T. (2021). Young Stroke Prevention Program for University Lecturers with Risk Factors via Smartphone Application. Open Journal of Social Sciences, 9, 108-119. https://doi.org/10.4236/jss.2021.98009

Received: July 13, 2021

Accepted: August 3, 2021

Published: August 6, 2021

Copyright ( 2021 by author(s) and Scientific Research Publishing Inc. This work is licensed under the Creative Commons Attribution International License (CC BY 4.0).

http://creativecommons.org/licenses/by/4.0/

\begin{abstract}
The major risk factors for young stroke patients were hypertension, diabetes, hyperlipidemia, waist circumference, and body mass index. This study evaluated the effectiveness of a young stroke prevention program for university lecturers via using a smartphone application. Research design was a quasiexperimental research one-group pretest-posttest design with using multistage random sampling. The study population were Kasetsart university lecturers $(\mathrm{n}=21)$ with risk factors for stroke, age between 20 - 45 years old. The 13 weeks program involved sending each subject weekly via a smart phone application information on stroke education, nutrition management and basic knowledge of exercise. Descriptive statistics were used to analyze the general characteristics, Inferential statistics to analyze the average scores pre-test and post-test, with stroke knowledge, weight, waist, body mass index (BMI), blood pressure level, attitude, and risk behavior were determined using a paired t-test statistic. The post-test results from the 21 respondents who participated indicated their knowledge level of stroke education was significantly higher than the pre-exposure, with mean pre-exposure and post-exposure scores of 7.81 and 9.10, respectively. Furthermore, body weight, waist size, systolic blood pressure, diastolic blood pressure and body mass index, were significantly lower by the end of the program. However, no significant differences were found for attitude nor for the subject behavior regarding risk factors of a stroke. This program can act as the guideline to reduce the incidence of young stroke by reducing risk factors and managing stroke prevention for university lecturers with risk factors of stroke.
\end{abstract}

\section{Keywords}

Young Stroke Prevention Program, University Lecturer, Risk Factors, Smartphone 


\section{Introduction}

The main objective of a university is to build the capability of the country's human resources in the professional and academic fields. University professors are an important driver in the process of creating graduates with desirable characteristics as specified by the program of the department, faculty and university. Therefore, university lecturers are a variable with important influence on graduate quality. In addition, university lecturers are considered personnel who play an important role in national development and this can be a heavy burden to carry, with average job stress among university lecturers being considered moderate; the primary factor influencing the work stress of university professors is educational quality assurance, followed by compensation burden and academic performance, respectively (Koo-Mgammak \& Siripanich, 2014). Therefore, university lecturers who are healthy, both physically and mentally, will be more effective in student development activities but their productivity regarding their roles, responsibilities and obligations, might be result in a lack of time for maintaining physical health that may result in non-communicable diseases (NCDs).

The World Health Organization listed NCDs as a major problem that is one of the leading global causes of death and is becoming increasingly serious and almost $70 \%$ of all deaths worldwide. Almost three quarters of all NCD deaths, and $82 \%$ of the 16 million people who died prematurely, or before reaching 70 years of age, occur in developing countries (World Health Organization, 2020). For Thailand, the latest statistics show that more than 14 million people are suffering from NCDs and most importantly, it is the leading cause of death for the entire country (Division of Non Communicable Disease, 2017). Cerebrovascular disease (stroke) is a one of main causes of death for Thai people which is a factor of risk behaviors, smoking, drinking alcohol, consuming sweet, salty, unhealthy diet and lack of physical activity (Suwanwela, 2014).

The number of new stroke victims reported that in the last 4 - 5 years globally has increased by at least 15 million people and 6 million people die from stroke each year which is greater than the 5 million people who have permanent disability (paralysis) (Division of Non Communicable Disease, 2016). In Thailand, almost 240,000 people are recorded as having each year and there is a real risk of this increasing to million people, especially for those having high blood pressure and diabetes. The stroke survivors, approximately 84,000 people a year will have paralysis (World Stroke Organization, 2019). The cost for an individual treatment is THB 100,000 - 1,000,000/year. The global statistics show that Thailand has more deaths than average and deaths will continue to increase in the future (World Health Organization, 2019). Stroke is a major health burden in Thailand. It is the leading cause of death and long term disability in both men and women (Suwanwela, 2014) and (Sribundit et al., 2017). The major risk factors for young stroke patients were hypertension, diabetes, hyperlipidemia, waist circumference, and body mass index (Chen et al., 2016). However, the cause of cerebrovascular disease among patients over 45 years differed from the young age group. There- 
fore, a primary stroke prevention program is particularly important because above $76 \%$ of strokes are first events (Meschia et al., 2014) and needed more focus by young adults. The present study is carried out the primary program to prevent young stroke for university lecturers with risk factors via smart phone application by provide stroke education, nutrition management and basic knowledge of exercise to reduce mortality rate and morbidity rate of young stoke in Thailand. This program is suitable and easy to follow which are related to the workload of university lecturers who have limited time. On the one hand, the program could be increased awareness of stoke prevention.

\section{Methodology}

\subsection{Study Design}

This study was a quasi-experimental research, involving pre-and post-test (onegroup, pretest-posttest design). The study population were Kasetsart university lecturers $(\mathrm{n}=21)$ with risk factors for stroke, age between 20 - 45 years old. The 13 weeks young stoke primary prevention program involved sending each subject weekly via a smart phone application information on stroke education, nutrition management and basic knowledge of exercise. In addition, the last activity program was food photos sharing in weeks $6-10$ and a food eating contest was conducted in week 12 .

\subsection{Study Population and Sampling Technique}

This study targeted university lecturers at Kasetsart University, Bang Khen campus, Bangkok, Thailand with high risk factors by using the guideline of assessing the risk of cardiovascular disease in high risk group of diabetes and hypertension High blood pressure (Pre-DM, Pre-HT) and people with obesity (Division of Non Communicable Disease, 2015). The sample group was determined using multistage random sampling. The first step divided the 15 faculties within the Bangkhen campus into 2 groups (science and non-science). Each group was selected by simple sampling. Each course group consisted of the following faculties: 1) Science: Faculty of Veterinary Science, Faculty of Veterinary Technology, Faculty of Environment, Faculty of Science, Faculty of Engineering, and Faculty of Agro-Industry; 2) Non-science: Faculty of Agriculture, Faculty of Economics, Faculty of Business Administration, Faculty of Architecture, Faculty of Fisheries, Faculty of Social Sciences, Faculty of Humanities, Faculty of Forestry, and Faculty of Education. The sampling resulted in the science group being represented by the Faculty of Veterinary Technology and the Faculty of Environment, while the non-science was represented by the Faculty of Education. Second step used purposive sampling to university lecturer. The risk factors for high-level stroke (3 - 4 risk factors) were in accordance with the guidelines by using the guideline of assessing the risk of cardiovascular disease in high risk group of diabetes and hypertension High blood pressure (Pre-DM, Pre-HT) and people with obesity.

Twenty-two university lecturers participated in this study. One participant 
was excluded from the data analysis because the follow-up survey was not completed. Therefore, the final analysis was restricted to twenty-one participants from three faculties. Twelve participants (57.1\% female) were recruited for this study. Age between 30 - 35 year old (38\%) and 36 - 40 year old (38\%). The average of monthly income for participants $30,000-40,000$ (31.8\%). Of these, all participants were not smoking. Eleven participant (52.4\%) had blood pressure $\geq$ $130 / 85$, nine participants $(42.9 \%$ ) had fasting plasma glucose $\geq 100 \mathrm{mg} / \mathrm{dl}$, sixteen participants $(76.2 \%)$ were diagnosed of high cholesterol and three participants $(14.3 \%)$ were diagnosed of ischemic heart disease or paralysis. More than fifty percent of participant (57.1\%) had waist greater than height (centimeters) divided by $2 \%$ and $66.7 \%$ had family history of ischemic heart disease or paralysis disease (men before age 55 years or women before age 65 years). The general characteristics of the subjects are listed in Table 1.

Table 1. General characteristics of subjects $(n=21)$.

\begin{tabular}{|c|c|}
\hline Characteristic & Frequency (percentage) \\
\hline \multicolumn{2}{|l|}{ Gender } \\
\hline Male & $9(42.9)$ \\
\hline Female & $12(57.1)$ \\
\hline \multicolumn{2}{|c|}{ Age of participants (years) } \\
\hline $30-35$ & $8(38)$ \\
\hline $36-40$ & $8(38)$ \\
\hline $41-45$ & $5(24)$ \\
\hline \multicolumn{2}{|c|}{ Monthly Income (THB) } \\
\hline $30,000-40,000$ & $8(38.1)$ \\
\hline $40,000-50,000$ & $6(28.6)$ \\
\hline$>50,000$ & $7(33.3)$ \\
\hline \multicolumn{2}{|l|}{ Smoking } \\
\hline Yes & $0(0)$ \\
\hline No & $21(100)$ \\
\hline \multicolumn{2}{|c|}{ Blood pressure $\geq 130 / 85 \mathrm{mmHg}$} \\
\hline Yes & $11(52.4)$ \\
\hline No & $10(47.6)$ \\
\hline \multicolumn{2}{|c|}{ Fasting plasma glucose $\geq 100 \mathrm{mg} / \mathrm{dl}$} \\
\hline Yes & $9(42.9)$ \\
\hline No & $12(57.1)$ \\
\hline
\end{tabular}


Continued

\begin{tabular}{cc}
\hline \multicolumn{2}{c}{ Diagnosis- High cholesterol } \\
\hline Yes & $16(76.2)$ \\
No & $5(23.8)$ \\
\hline Diagnosis-Ischemic heart disease or paralysis & $3(14.3)$ \\
\hline Yes & $18(85.7)$ \\
\hline No & $12(57.1)$ \\
\hline Yize of the waist greater than height (centimeters) divided by 2 & $9(42.9)$ \\
\hline No & $14(66.7)$ \\
\hline $\begin{array}{c}\text { Have a family history of ischemic heart disease or paralysis } \\
\text { disease (men before age } 55 \text { years or women before age 65 years) }\end{array}$ & $7(33.3)$ \\
\hline Yes & \\
\hline
\end{tabular}

\subsection{Intervention}

To develop and evaluate these young stoke primary prevention program, the researcher 1) analyzed the contents and effects of stroke prevention programs in previous studies; 2) developed our stroke prevention program; 3) implemented the program; and 4) analyzed and evaluated the effectiveness of the program. The contents of the program consisted of stroke education, nutrition education and management, and exercise guidance. The 13-week program included 3 sessions using a brochure sent to participants via a smart phone application once a week. The sessions were the following:

1) Stroke education including knowledge of cerebrovascular disease, definition, cause of stroke, symptom and stroke management, risk factors of stroke, stroke risk factor management (diabetes management, hyperlipidemia management, obesity management, cerebrovascular disease prevention, low sodium diet and low cholesterol diet, drinking and smoking), stress management and stress coping and stroke and first aids management.

2) Nutrition education and management including stroke prevention exercise; the five main food groups, Low sodium diet, Low sodium diet assessment per household, Low sodium diet menu, Dietary assessment sugar, Low-carb diets, Low cholesterol diet, Low cholesterol diet menu and Stroke prevention diet menu recommendation.

3) Basic knowledge of exercise to prevent a stroke including flexibility exercises, simple aerobic exercises (fast walk aerobic exercise and slow running exercise), balance exercise, aerobic exercise, yoga exercise, DaoDejing exercise.

In addition, food exchange was conducted in weeks 6 - 10 and a food prevention eating contest was conducted in week 11 . The program activities are shown in Table 2. 
Table 2. Program activity week 0 - 13 for Primary prevention program for Kasetsart university lecturers with risk factors to prevent young stroke via smart phone application.

\begin{tabular}{|c|c|c|}
\hline Week & \multicolumn{2}{|c|}{$\begin{array}{l}\text { Activity and contents of Primary prevention program for Kasetsart university lecturers with risk factors to } \\
\text { prevent young stroke via smart phone application }\end{array}$} \\
\hline \multirow[t]{2}{*}{$\begin{array}{l}\text { Week } 0 \\
\text { (Baseline/Pre-exposure) }\end{array}$} & Activity & $\begin{array}{l}\text { Vital sign, weight, height, waist circumference and body mass index measurement and pre-test: } \\
\text { knowledge of cerebrovascular disease, definition and causes of stroke }\end{array}$ \\
\hline & Education & Knowledge of cerebrovascular disease, definition and causes of stroke \\
\hline \multirow[t]{3}{*}{ Week 1} & Exercise & Stroke prevention exercise: Flexibility exercises, 3 times a week, 30 minutes per time \\
\hline & Nutrition & The five main food groups \\
\hline & Education & Symptoms and stroke management \\
\hline \multirow[t]{2}{*}{ Week 2} & Exercise & $\begin{array}{l}\text { Stroke prevention exercise: Simple aerobic exercises (fast walk aerobic exercise and slow running } \\
\text { exercise), } 3 \text { times a week, } 30 \text { minutes per time }\end{array}$ \\
\hline & Nutrition & Low sodium diet \\
\hline \multirow{3}{*}{ Week 3} & Education & Risk factors of stroke \\
\hline & Exercise & Stroke prevention exercise: Flexibility exercises, 3 times a week, 30 minutes per time \\
\hline & Nutrition & Low sodium diet assessment per household \\
\hline \multirow{5}{*}{ Week 4} & Activity & Vital sign, weight, height, waist circumference and body mass index measurement \\
\hline & Education & Stroke risk factors management \\
\hline & \multirow{2}{*}{ Exercise } & - 3 times a week, 35 minutes per time \\
\hline & & - Flexibility exercise and balance exercise \\
\hline & Nutrition & Low sodium diet menu \\
\hline \multirow{5}{*}{ Week 5} & \multirow{2}{*}{ Education } & Stroke risk factors management \\
\hline & & Diabetes management \\
\hline & \multirow{2}{*}{ Exercise } & - 3 times a week, 40 minutes per time \\
\hline & & - Aerobic exercise \\
\hline & Nutrition & Dietary assessment sugar \\
\hline \multirow{6}{*}{ Week 6} & \multirow{2}{*}{ Education } & Stroke risk factors management \\
\hline & & Hyperlipidemia management \\
\hline & \multirow{3}{*}{ Exercise } & Stroke prevention exercise \\
\hline & & - 3 times a week, 40 minutes per time \\
\hline & & - Aerobic exercise (cont.) \\
\hline & Nutrition & Sharing food photos among the group \\
\hline \multirow{6}{*}{ Week 7} & \multirow{2}{*}{ Education } & Stroke prevention \\
\hline & & - Obesity management \\
\hline & \multirow{3}{*}{ Exercise } & Stroke prevention exercise \\
\hline & & -3 times a week, 50 minutes per time \\
\hline & & - Aerobic exercise (cont.) \\
\hline & Nutrition & Low-carb diets \\
\hline
\end{tabular}




\section{Continued}

\begin{tabular}{|c|c|c|}
\hline \multirow{8}{*}{ Week 8} & Activity & Vital sign, weight, height, waist circumference and body mass index measurement \\
\hline & & Stroke prevention \\
\hline & Education & - Cerebrovascular disease prevention \\
\hline & & - Benefits of exercise \\
\hline & & Stroke prevention exercise \\
\hline & Exercise & - 3 times a week, 50 minutes per time \\
\hline & & - Yoga exercise \\
\hline & Nutrition & Low cholesterol diet \\
\hline \multirow{6}{*}{ Week 9} & Educotion & Stroke prevention \\
\hline & 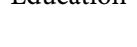 & - Nutrition: Low sodium diet and low cholesterol diet \\
\hline & & Stroke prevention exercise: Stabilization period \\
\hline & Exercise & - 3 times a week, 50 minutes per time \\
\hline & & - Yoga exercise (cont.) \\
\hline & Nutrition & Low cholesterol diet menu \\
\hline \multirow{6}{*}{ Week 10} & & Stroke prevention \\
\hline & Lulucalionit & - Drinking and smoking \\
\hline & & Stroke prevention exercise \\
\hline & Exercise & - 3 times a week, 50 minutes per time \\
\hline & & - DaoDeJing exercise, it is a movement meditation (Dynamic) \\
\hline & Nutrition & Stroke prevention diet menu recommendation \\
\hline \multirow{6}{*}{ Week 11} & Fducation & Stroke prevention \\
\hline & 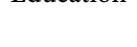 & - Stress management and stress coping \\
\hline & & Stroke prevention exercise: Stabilization period \\
\hline & Exercise & - 3 times a week, 50 minutes per time \\
\hline & & - DaoDeJing exercise (cont.) \\
\hline & Nutrition & Stroke prevention diet menu recommendation \\
\hline \multirow{5}{*}{ Week 12} & Education & Stroke and first aid management \\
\hline & Fremcico & Stroke prevention exercise \\
\hline & & -3 times a week, 50 minutes per time \\
\hline & & - DaoDeJing exercise (cont.) \\
\hline & Nutrition & Stroke prevention cooking contest for one week by sharing cooking photos among the group \\
\hline $\begin{array}{l}\text { Week } 13 \\
\text { (post-exposure) }\end{array}$ & Activity & $\begin{array}{l}\text { Vital sign, weight, height, waist circumference, body mass index measurement and post-test: } \\
\text { knowledge of cerebrovascular disease, definition and causes of stroke }\end{array}$ \\
\hline
\end{tabular}

\subsection{Data Collection}

Measurements of subjects were taken during at the baseline visit (week 0) in the following order: blood pressure, height, weight, and waist size. This study was a quasi-experimental research involving pre-and post-testing (one-group, pretest-posttest design) from the population defined as the sample of university lec- 
turers in Kasetsart University with stroke risk factors. Data were collected before and after conducting the program and the results were compared regarding changes in health behavior in exercising, eating and controlling body weight in a manner suitable for the lifestyle and working context of the university. Written consent and voluntary participation in this research were obtained from each participant. The duration of the study was between May to September 2019 for a total of 13 weeks.

\subsection{Data Analysis}

Data analysis in this research used Statistical analysis software to obtain: 1) descriptive statistics, with the general characteristics analyzed using frequency, mean, and percentage; 2) Inferential statistics to analyze the average scores pre-test and post-test, with stroke knowledge, weight, waist, body mass index (BMI), blood pressure level, attitude, and risk behavior were determined using a paired t-test statistic.

\subsection{Ethical Consideration}

The proposal was approved by the Kasetsart University Research and Development Institute, reference number KURDI COA No. 62/018 date 9 April 2019. The researcher informed the study purpose to all participants before performing any activities. The confidentiality of participants in this study (their name and personal information) was ensured by not reporting such information.

\section{Results}

The electronic brochures including the 3 sessions were sent to the subjects via a smart phone application once a week. The effect of the stroke primary prevention program is summarized below:

Knowledge: Stroke education covering causes, signs and symptoms, stroke management, risk factors of stroke, high blood pressure management, high blood glucose management, high cholesterol management, obesity management, and stroke \& first aid management were provided to each subject. There was a significant increase between the baseline (7.81) and post-exposure measurements (9.10), $(\mathrm{t}=-2.631, p<0.016)$.

Nutrition education \& management: The contents focused on the type of food and a healthy diet to prevent a future stroke. In addition, there was food photo sharing among the group in week 6 , with the subjects sharing their food photos for 3 meals, including snacks or extra food. Most of the food photos contained healthy food, as they wanted to show the healthy food they had eaten. A food contest was run in week 12 to encourage the subjects to choose menu items to prevent a stroke, with the winner of this contest being a basic healthy menu, including vegetables with homemade salad.

Basic knowledge of exercise to prevent a stroke: Basic exercises covering flexibility, balance, aerobics, DaoDeJing, and yoga were provided to the subjects 
during the program. All exercises were basic and could be done everywhere, even at work. Basic exercise can help to control high blood pressure, which is an important risk factor for stroke, and exercise can help to control other things that have a high stroke risk, such as obesity, high cholesterol and diabetes, which are related to the workload of university professors who have limited exercise time. Furthermore, the subjects had limited equipment, but during the program they were encouraged to exercise in their working area using the study electronic brochure information.

Attitude: No significant differences were found pre-and post-test regarding attitude because the subjects had a positive attitude regarding stroke prior to the program $(\mathrm{t}=-0.519, p=0.609)$.

Risk behavior: The subject's behavior as a risk factor of stoke was not significant after the program $(\mathrm{t}=-1.248, p=0.227)$.

\section{Homogeneity of dependent variables}

Waist: This measurement was significantly lower after the program, from the pre-exposure mean of $87.548 \mathrm{~cm}$ to post-exposure $85.595 \mathrm{~cm}(\mathrm{t}=9.191, p=$ $0.000^{*}$.

Body weight: After the program, the body weight decreased significantly from the pre-exposure mean score of $71.071 \mathrm{~kg}$ to $69.024 \mathrm{~kg}(\mathrm{t}=5.035, p=$ $0.000^{*}$ ).

Body Mass Index (BMI): The BMI decreased significantly from a pre-exposure mean of 25.884 to a post-exposure mean of $25.214\left(\mathrm{t}=4.938, p=0.000^{*}\right)$.

Blood pressure: The systolic blood pressure and diastolic blood pressure were both significantly different before and after the program. However, Systolic blood pressure decreased from a mean of $127.67 \mathrm{mmHg}$ before the experiment to $118.10 \mathrm{mmHg}$ after the experiment $\left(\mathrm{t}=3.050, p=0.006^{*}\right)$ and the diastolic blood pressure decreased from a mean score of $84.0 \mathrm{mmHg}$ prior the experiment to $75.0 \mathrm{mmHg}$ after the experiment $\left(\mathrm{t}=3.111, p=0.006^{*}\right)$. The results on the homogeneity of the dependent variables are presented in Table 3.

Table 3. Effectiveness of program based on homogeneity of dependent variables $(n=21)$.

\begin{tabular}{|c|c|c|c|c|c|c|}
\hline & & \multicolumn{2}{|c|}{ Pre-exposure/Baseline } & \multicolumn{2}{|c|}{ Post-exposure } & \multirow[b]{2}{*}{$\begin{array}{c}\text { Sig. } \\
\text { (2 tailed) }\end{array}$} \\
\hline & & Mean & Mean & Correlation & $\mathrm{t}$ & \\
\hline Waist $(\mathrm{cm})$ & & 87.549 & 85.595 & 0.996 & 9.191 & $0.000^{*}$ \\
\hline Body weight (kg) & & 71.071 & 69.024 & 0.991 & 5.035 & $0.000^{*}$ \\
\hline $\begin{array}{l}\text { Body Mass Index } \\
\text { (BMI) }\end{array}$ & & 25.884 & 25.214 & 0.993 & 4.938 & $0.000^{*}$ \\
\hline \multirow[t]{2}{*}{$\begin{array}{l}\text { Blood pressure } \\
\quad(\mathrm{mmHg})\end{array}$} & $\begin{array}{l}\text { Systolic blood } \\
\text { pressure (SBP) }\end{array}$ & 127.62 & 118.10 & 0.732 & 3.050 & $0.006^{*}$ \\
\hline & $\begin{array}{l}\text { Diastolic blood } \\
\text { pressure (DBP) }\end{array}$ & 84.0 & 75.0 & 0.513 & 3.111 & $0.006^{*}$ \\
\hline
\end{tabular}

Note: $p$-value $<0.05$. 


\section{Discussion}

This study evaluated the effectiveness of a young stroke prevention program for university lecturers via using a smart phone application. The results showed that the average scores for stroke education, body weight, waist, body mass index (BMI) and blood pressure (systolic and diastolic blood pressure) from the pre-test and post-test programs were significantly higher/ better than before the program. These results were consistent with a study by Krishnamurthi et al., 2019 study Mobile technology for primary stroke prevention: a proof-of-concept pilot randomized controlled trial for smart phone application, found that overall results were positive feedback with some positive lifestyle behavior changes such as diet, number of cigarettes smoked, blood pressure, and weight. This study was quasi experimental research involving one-group pretest-posttest design with 13 weeks program included 3 sessions consisting of stroke education in weeks 1 12 , nutrition education and management in weeks $2-12$ and basic knowledge of exercise to prevent a stroke in weeks 2 - 12 by using the electronic brochure sent to participants via the smart phone application once a week, and weeks 13, post exposure activity including vital sign, weight, height, waist circumference, body mass index measurement and post-test were performed to the subjects. The contents of the program consisted of: 1) stroke education providing definitions, causes, signs and symptoms, stroke management, risk factor of stroke, high blood pressure management, high blood glucose management, high cholesterol management, obesity management, and stroke \& first aid management; 2) nutrition education and management were conducted in this program with five main food groups, sodium diet, cholesterol diet, carbohydrate diet and recommended foods were emphasized to prevent stroke. 3) Basic knowledge of exercise to prevent a stroke was provided to the participants, focusing on basic exercise to help control blood pressure, weight and body mass index (BMI).

In addition, the last activity program was food photos sharing in weeks $6-10$ and a food eating contest was conducted in week 12. These exercises aimed to raise the awareness of the subjects regarding proper healthy eating or developing a meal plan, with the aim to make the subjects aware of diet stroke prevention. This result was associated with research by Jeon \& Jeong, 2015, which examined the effects of the primary stroke prevention program on risk factors for the elderly at home. They reported that the 13 weeks of activities were effective with stoke education, nutrition education and management, and basic knowledge of exercise helping to prevent a stroke. On the other hand, no significant differences were found for attitude. Similarly, the subject's behavior toward the risk factors of stoke were not significantly different prior the program because this study did not provide an intervention program among the subject that focused on individual attitude and behavioral change. This result was associated with research by Steinmetz et al., 2016 which was explored how effective are Behavior Change Interventions Based on the Theory of Planned Behavior, from the result found that the interventions conducted in public and with groups were more 
successful than interventions in private locations or focusing on individuals. Furthermore, the researchers applied the stroke risk assessment by using the guideline of assessing the risk of cardiovascular disease in high risk group of diabetes and hypertension High blood pressure (Pre-DM, Pre-HT) and people with obesity (Division of Non Communicable Disease, 2015), because the guidelines were similar for stroke risk assessment. The risk factors in the guideline were consistent those from a research study by Chen et al., 2016 stated that the high risk groups for a stroke were: hypertension, diabetes, hyperlipidemia, waist circumference, and body mass index. This was consistent with research by Pan et al., 2019 who studied the relationship between smoking and a stroke. The study was carried out using a systematic review of 14 research studies with a target population of 303, 134 and found that smokers had more risk factors for stroke than non-smokers and, according to this study, smoking has also been proven to be associated with diabetes, high blood pressure and elevated resting heart rate, all of which are risk factors for a stroke. The data obtained from this study will be used in planning a program for stroke prevention among young university lecturers to meet the health needs in their daily life and routine work.

\section{Conclusion}

From this study, it can be concluded that properly organizing a program without compromising on the core workload of university lecturers will benefit the subjects if they commit to using a simple smart phone application once per week as a stimulating and educational process that includes group activities. This may make the university lecturers more stroke knowledge and aware of the diet choices and basic exercise to prevent a young stroke.

\section{Suggestion}

The limitation of this study was its small sample size due to the limited number of university lecturers satisfying the eligibility criteria. Further studies with larger sample sizes would be beneficial to conduct a more detailed analysis.

\section{Conflicts of Interest}

The author declares no conflicts of interest regarding the publication of this paper.

\section{References}

Chen, R., Ovbiagele, B., \& Feng, W. (2016). Diabetes and Stroke: Epidemiology, Pathophysiology, Pharmaceuticals and Outcomes. The American Journal of the Medical Sciences, 351, 380-386. https://doi.org/10.1016/j.amjms.2016.01.011

Division of Non Communicable Disease (2016). Manual of Quality NCD Clinic Operations Fiscal Year 2016 (pp. 1-17). Bureau of Non Communicable Disease, Ministry of Public Health.

http://thaincd.com/2016/media-detail.php?id=11003\&tid=1-001-005,31,29\&gid=1-026

Division of Non Communicable Disease (2017). Situation on NDCs Prevention and Con- 
trol in Thailand (pp. 1-60). Bureau of Non Communicable Disease, Ministry of Public Health.

http://www.thaincd.com/document/file/download/paper-manual/NCDUNIATF61.pdf

Division of Non Communicable Disease, Bureau of Non-Communicable Diseases, Ministry of Public Health (2015). Guideline for Assessment of Cardiovascular Disease Risk: Assessing the Risk of Cardiovascular Disease in High Risk Group of Diabetes and Hypertension High Blood Pressure (Pre-DM, Pre-HT) and People with Obesity (p. 18). Office of Printing Affairs, the War Veterans Organization.

Jeon, M. Y., \& Jeong, H. (2015). Effects of a Stroke Primary Prevention Program on Risk Factors for At-Home Elderly. Medical Science Monitor, 21, 3696-3703.

https://doi.org/10.12659/MSM.895519

Koo-mgammak, J., \& Siripanich, P. (2014). Work Stress of Instructors in State Universities. NIDA Development Journal, 54, 259-285.

Krishnamurthi, R., Hale, L., Barker-Collo, S., Theadom, A., Bhattacharjee, R., George, A., Arroll, B., Ranta, A., Waters, D., Wilson, D., Sandiford, P., Gall, S., Parmar, P., Bennett, D., \& Feigin, V. (2019). Mobile Technology for Primary Stroke Prevention. Stroke, 50, 196-198. https://doi.org/10.1161/STROKEAHA.118.023058

Meschia, J. F., Bushnell, C., Boden-Albala, B., Braun, L. T., Bravata, D. M., Chaturvedi, S., Creager, M. A., Eckel, R. H., Elkind, M. S. V., Fornage, M., Goldstein, L. B., Greenberg, S. M., Horvath, S. E., Iadecola, C., Jauch, E. C., Moore, W. S., \& Wilson, J. A. (2014). Guidelines for the Primary Prevention of Stroke: A Statement for Healthcare Professionals from the American Heart Association/American Stroke Association. Stroke, 45, 3754-3832.

Pan, B., Jin, X., Jun, L., Qiu, S., Zheng, Q., \& Pan, M. (2019). The Relationship between Smoking and Stroke: A Meta-Analysis. Medicine (Baltimore), 98, e14872. https://doi.org/10.1097/MD.0000000000014872

Sribundit, N., Riewpaiboon, A., Chaikledkaew, U., Stewart, J., Tantirittisak, T., \& Hanchaipiboolkul, S. (2017). Cost of Acute Care for Ischemic Stroke in Thailand. The Southeast Asian Journal of Tropical Medicine and Public Health, 48, 628-640.

Steinmetz, H., Knappstein, M., Ajzen, I., Schmidt, P., \& Kabst, R. (2016). How Effective Are Behavior Change Interventions Based on the Theory of Planned Behavior? A ThreeLevel Meta-Analysis. Zeitschrift für Psychologie, 224, 216-233. https://doi.org/10.1027/2151-2604/a000255

Suwanwela, N. C. (2014). Stroke Epidemiology in Thailand. Journal of Stroke, 16, 1-7. https://doi.org/10.5853/jos.2014.16.1.1

World Health Organization (2019). Hypertension Care in Thailand: Best Practices and Challenges, 2019 (pp. 1-76). World Health Organization, Country Office for Thailand. https://apps.who.int/iris/handle/10665/330488

World Health Organization (2020). Noncommunicable Diseases. https://www.who.int/health-topics/noncommunicable-diseases\#tab=tab 1

World Stroke Organization (WSO) (2019). Global Stroke Fact Sheet 2019 (pp. 1-22). https://www.world-stroke.org/assets/downloads/WSO Fact-sheet 15.01.2020.pdf 